\section{$\checkmark$ Research Square}

\title{
Klinefelter Syndrome with Azoospermia】 Identification of a Neocentromic Y Chromosome with No Detectable DYZ3 Centromeric Sequence
}

Qiong Wu ( $\sim$ qiongwu_tjmu@126.com )

Xiamen Maternity and Child Health Hospital https://orcid.org/0000-0002-4796-3926

Yu-Lin Zhou

Xiamen Maternity and Child Health Hospital

Hui Kong

Xiamen Maternity and Child Health Hospital

Yun-Sheng GE

xiamen maternity and child health hospical

Yan-Yan Shen

xiamen maternity and child health hospital

Qi-Wei Guo

xiamen maternity and child health hospital

Xin-Li Huang

BUSM: Boston University School of Medicine

\section{Case Report}

Keywords: Klinefelter Syndrome, neocentromere, Fluorescence in Situ Hybridization

Posted Date: January 15th, 2021

DOl: https://doi.org/10.21203/rs.3.rs-146030/v1

License: (c) (i) This work is licensed under a Creative Commons Attribution 4.0 International License.

Read Full License 


\section{Abstract}

Background Individuals with rare cytogenetic variants have contributed to our understanding of the genetics of sex chromosome and its disorders. Here, we report on a 23 years old man with a de novo 47,XX,+mar.ish der(Y)neo(Y)(pter->p11.2::q11.23-->neo->q11.23-->qter)(DYZ3-,SRY+,WCPY+) chromosome complement, accompanying with azoospermia and some of other clinical features suggestive of Klinefelter's Syndrome. The constitution of the patient was verified by GTG-banding, QFQbanding, Fluorescence in Situ Hybridization and Polymerase Chain Reaction. Accordingly, we report the finding of a structurally abnormal chromosome $Y$ with no detectable DYZ3 centromeric sequence and with no detection of AZF a, AZF b and AZF c, with clinical features suggestive of Klinefelter's Syndrome. This is the first reported case of Klinefelter's Syndrome involving a neocentromic $Y$ among previously described cases with a neocentromere.

Case presentation we report on a 23 years old man with a de novo 47,XX,+mar.ish $\operatorname{der}(\mathrm{Y})$ neo( $\mathrm{Y})(\mathrm{pter}-$ $>$ p11.2::q11.23-->neo->q11.23-->qter)(DYZ3-,SRY+,WCPY+) chromosome complement, accompanying with azoospermia and some of other clinical features suggestive of Klinefelter's Syndrome. The constitution of the patient was verified by GTG-banding, QFQ-banding, Fluorescence in Situ Hybridization FISH and Polymerase Chain Reaction PCR.

Conclusions It can be inferred that a neocentromic $Y$ is formed by identification of FISH, PCR and the fact that this markerof $Y$ chromosome is present in $100 \%$ of peripheral blood cells and has been efficiently retained through cell divisions despite the absence of the endogenous centromere region. To our knowledge, this is the first reported case of Klinefelter's Syndrome involving a neocentromic $Y$ among previously described cases with a neocentromere, which adds to the catalog of chromosomal aberrations. The present study not only improves the understanding of karyotype/phenotype relationships between neocentric marker $Y$ chromosomes and KFS male infertility, but also supports the hypothesis that the combined application of molecular cytogenetic analysis might help to identify breakpoints, origins, and the constitution of the marker chromosomes.

\section{Full Text}

Due to technical limitations, full-text HTML conversion of this manuscript could not be completed. However, the latest manuscript can be downloaded and accessed as a PDF.

\section{Figures}




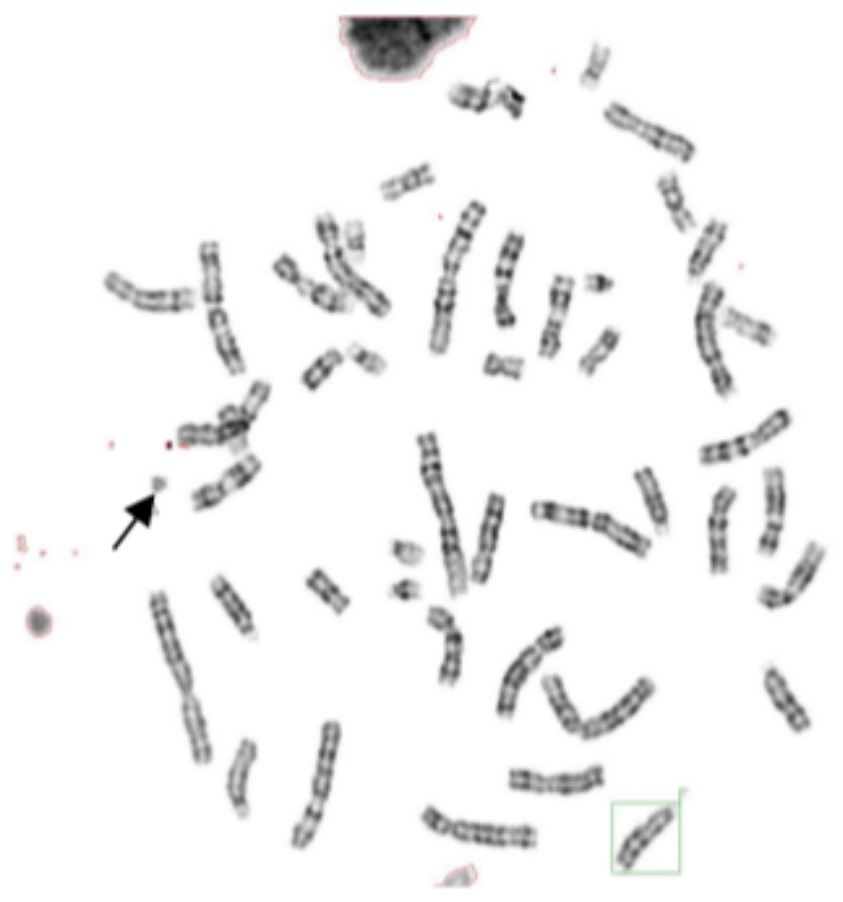

Figure 1

karyotype of the marker chromosome: the arrow shows the mar chromosome in metaphase by GTG banding, suggesting a mar chromosome similar to chromosome $\mathrm{Y}$, while smaller than usual.
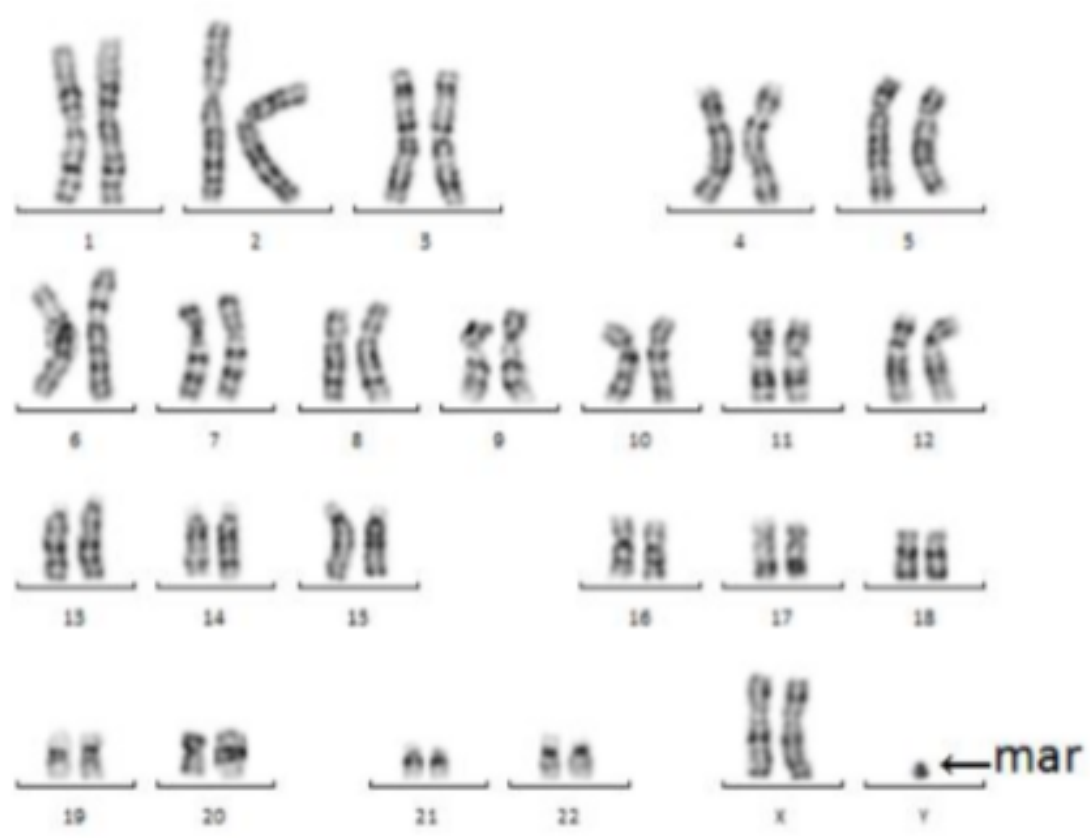

Figure 2

karyotype of the marker chromosome: the arrow shows the mar chromosome in metaphase by GTG banding, suggesting a mar chromosome similar to chromosome $Y$, while smaller than usual. 


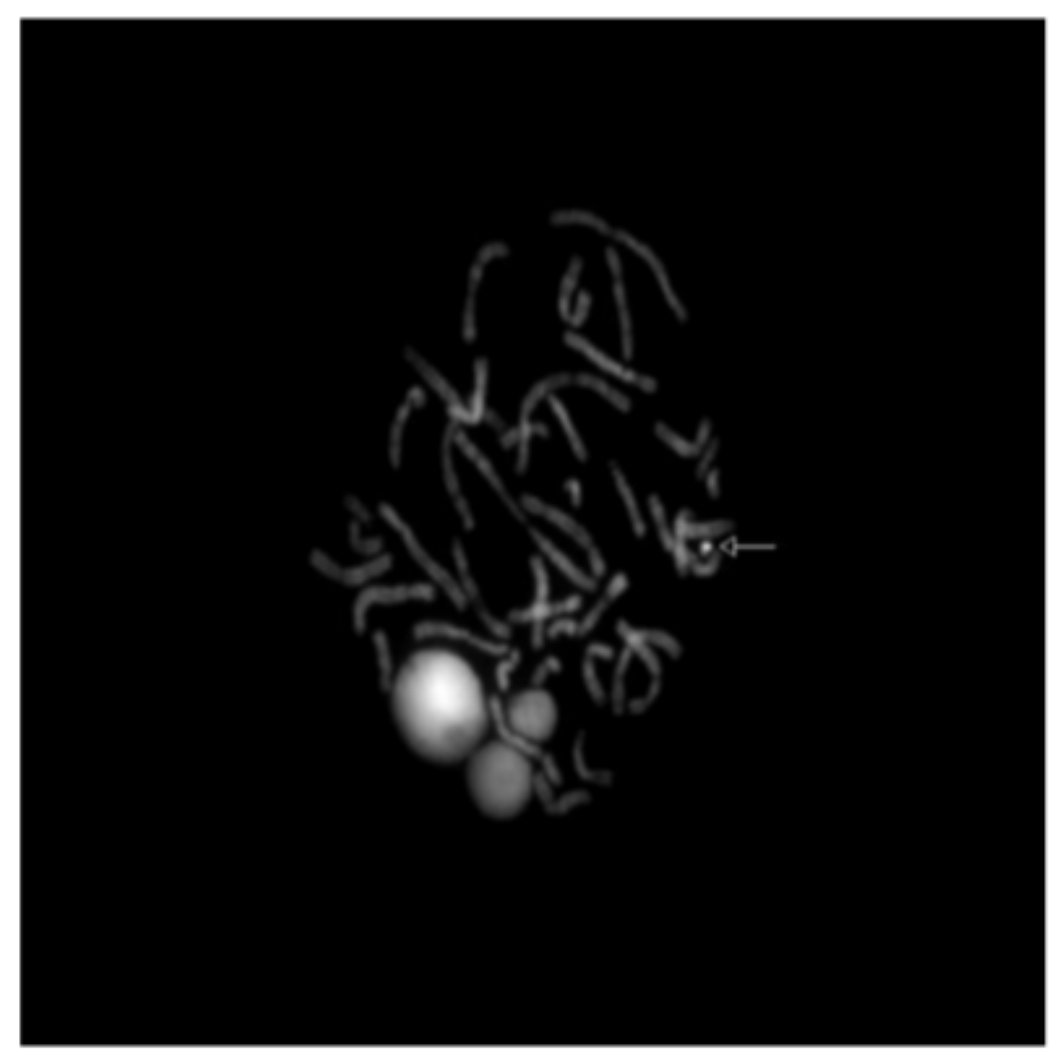

Figure 3

The arrow shows the mar chromosome in metaphase by QFQ banding, which is positive indicating the presence of heterochromatin.

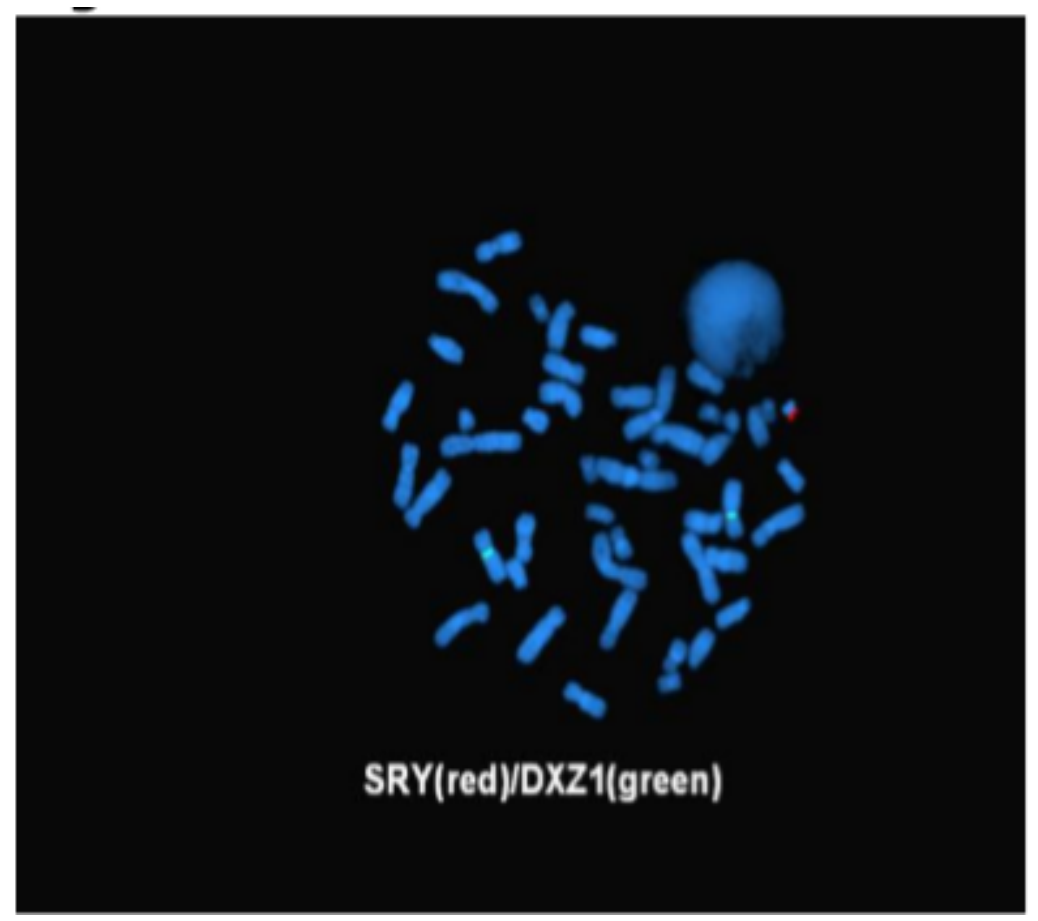

Figure 4 
Hybridization of SRY(red) probe and X chromosome centromere-specific probe DXZ1(green) revealed two copies of hybridization of the normal $X$ chromosome and one copy of SRY in metaphase and in interphase respectively.

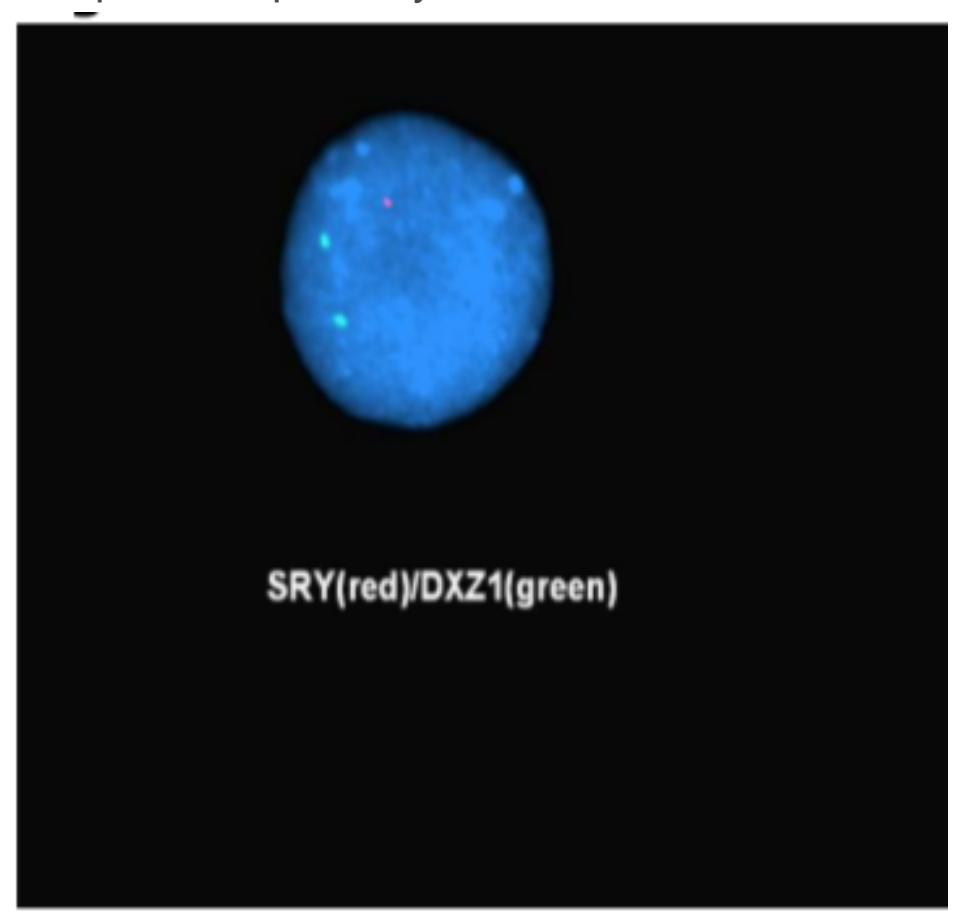

Figure 5

Hybridization of SRY(red) probe and X chromosome centromere-specific probe DXZ1 (green) revealed two copies of hybridization of the normal $X$ chromosome and one copy of SRY in metaphase and in interphase respectively.

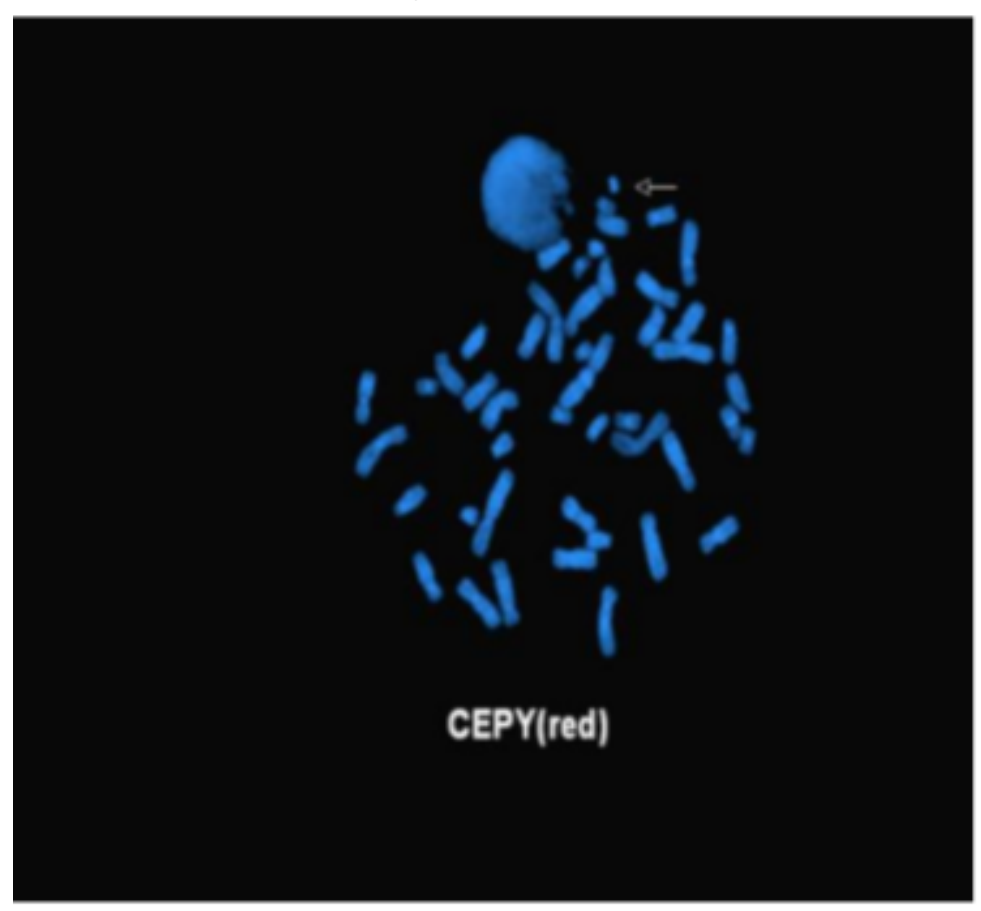

Figure 6 
The arrow shows the mar chromosome in metaphase wasn't hybridized by the $Y$ centromere-specific probe CEPY(red) and DYZ3(red), indicating lcck or inactivation of the conventional centromere of $Y$ chromosome.

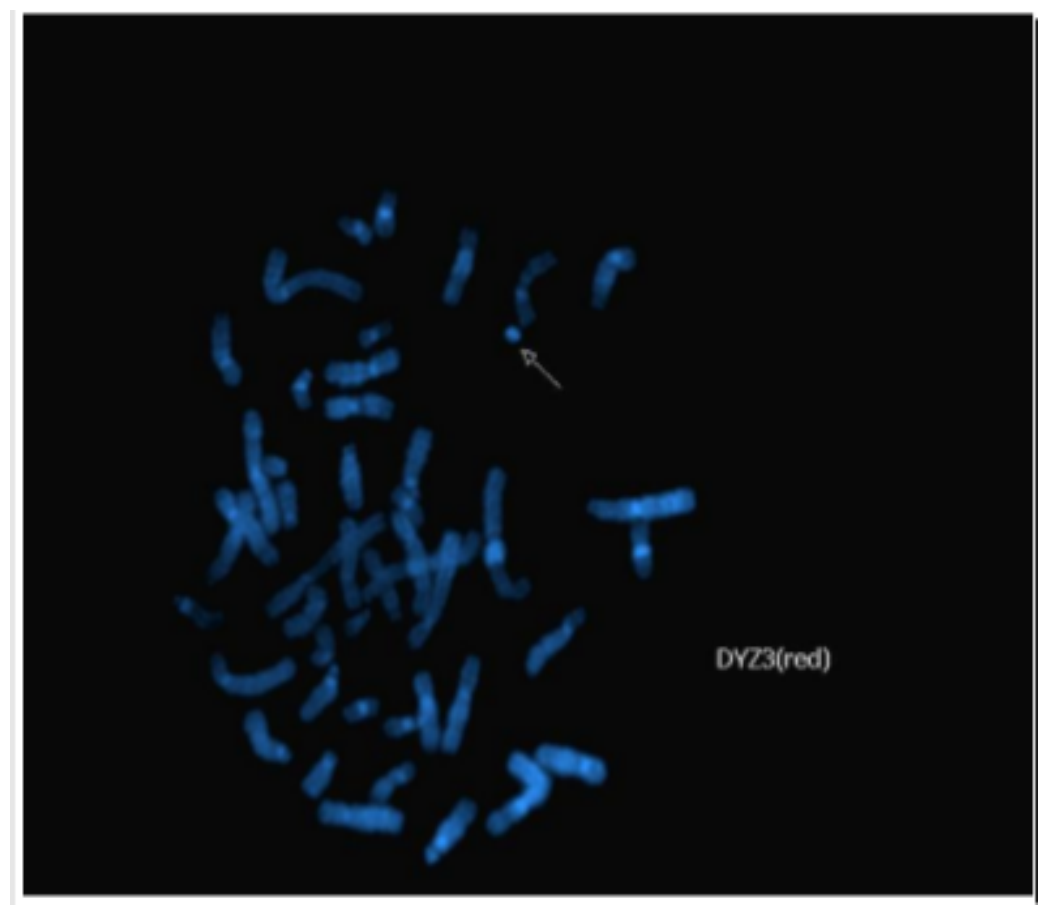

Figure 7

The arrow shows the mar chromosome in metaphase wasn't hybridized by the $Y$ centromere-specific probe CEPY(red) and DYZ3(red), indicating lcck or inactivation of the conventional centromere of $Y$ chromosome.

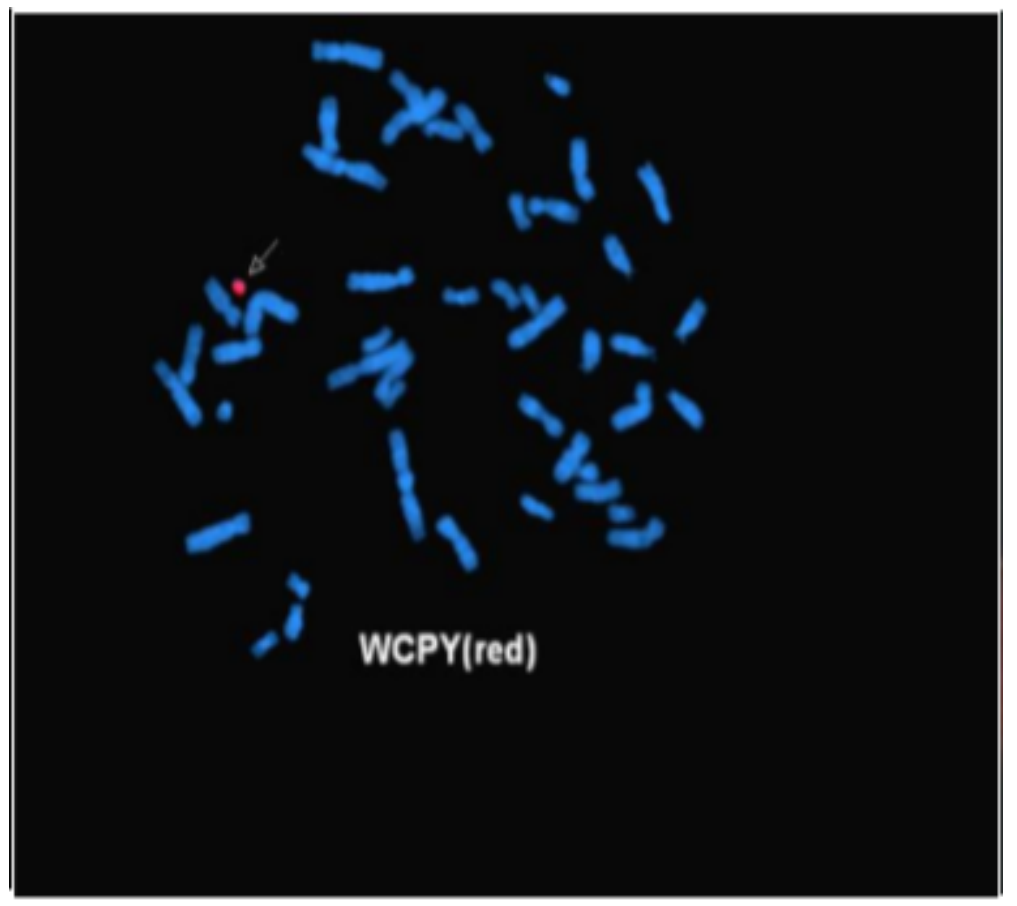

Figure 8 
Whole chromosome smear probe of $\mathrm{Y}(\mathrm{WCPY})$ (red)showed the mar chromosome originated only from chromosome Y.

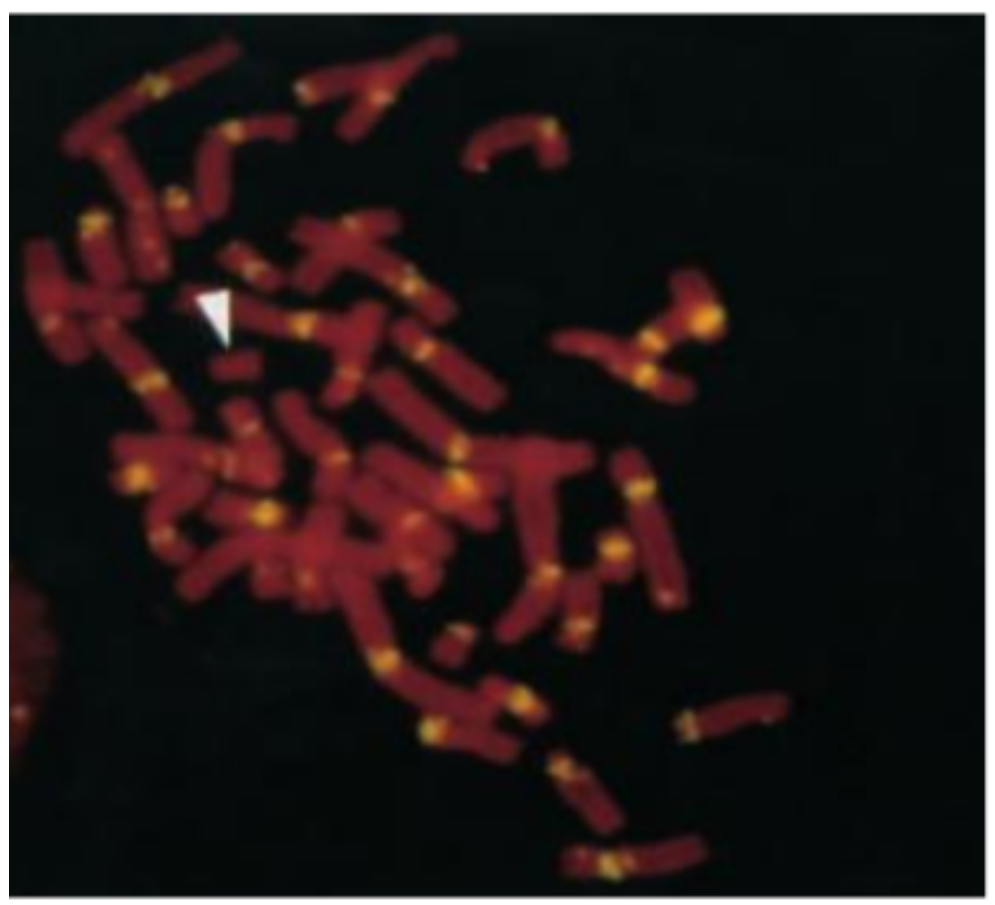

\section{Figure 9}

All huaman centromere probes(yellow) showed positive hybridization of all centromeres except the mar chromosome

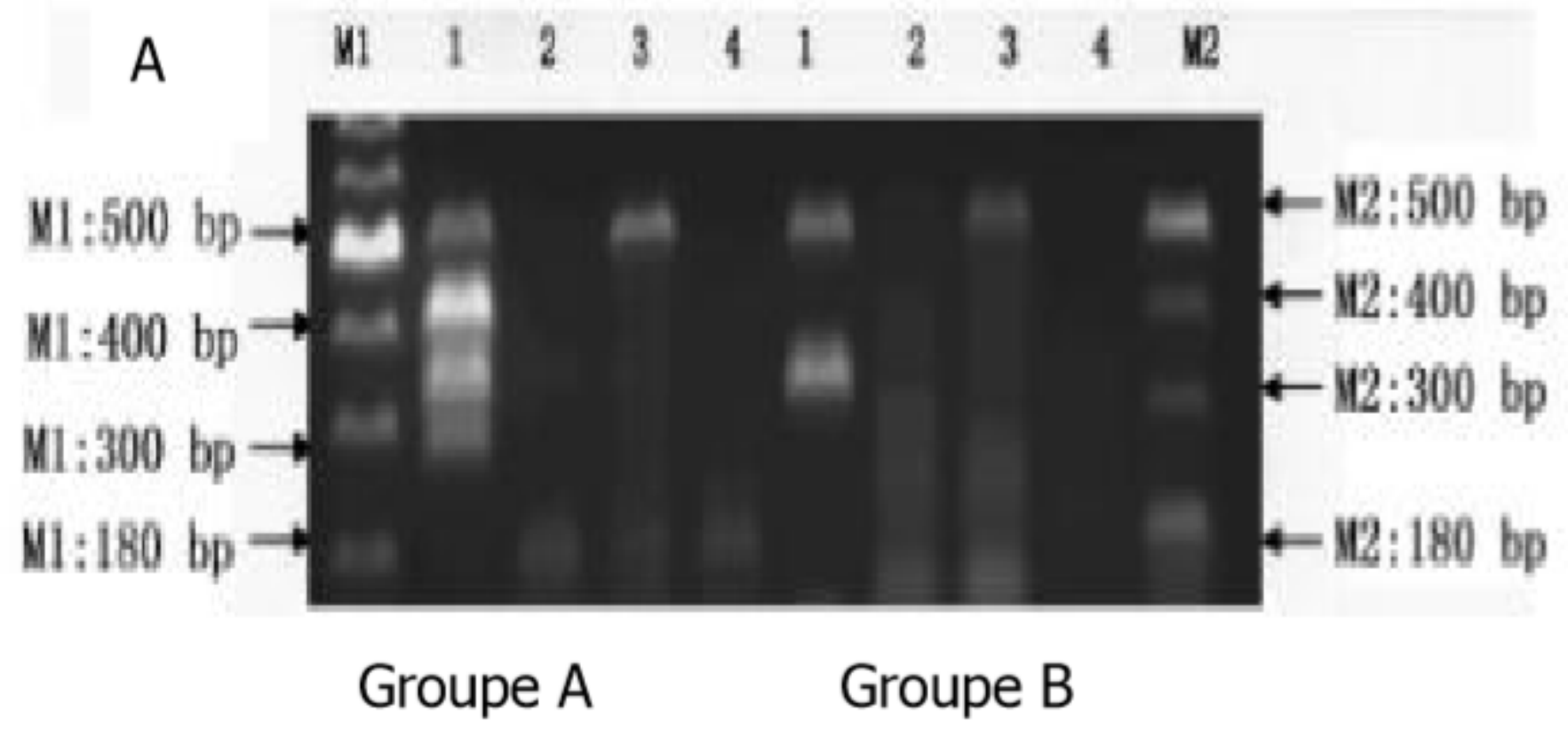

Figure 10

Mapping of mar by detection of AZF microdeletion.1:Positive control normal male.2:Negative control normal female. 3: Patient with microdeletions of azf $a$, azf $b$ and azf $c$ locuses, SRY positive.4: Blank 
control.M1\& M2: marker.

\begin{tabular}{|c|c|c|c|c|c|c|c|}
\hline & & & \multirow[t]{2}{*}{ Sequence } & \multirow[t]{2}{*}{$\mathrm{Y}$ chromosome interval } & \multirow[t]{2}{*}{ Patient } & \multirow[t]{2}{*}{ Male control } & \multirow{2}{*}{ Female control } \\
\hline 113 & 11132 & & & & & & \\
\hline 112 & $\begin{array}{ll}2 & 1131 \\
3 & \end{array}$ & & SRY & 1 & + & + & - \\
\hline 111.1 & $4 \begin{array}{r}112 \\
414\end{array}$ & $\begin{array}{l}\text { inactivated of mised } \\
\text { centromere }\end{array}$ & STS 84 & 5 & - & + & - \\
\hline & $5 \quad \begin{array}{ll}1121 \\
1121\end{array}$ & & STS 86 & 5 & - & + & - \\
\hline 112 & $6 \quad 11223$ & $\longrightarrow$ Neocentromerey & STS 127 & 5 & - & + & - \\
\hline 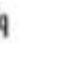 & 1130 & & STS 134 & 5 & - & + & - \\
\hline & 12 & & STS 254 & 6 & - & + & - \\
\hline 12 & 1 & & STS 255 & 6 & - & + & - \\
\hline
\end{tabular}

\section{Figure 11}

Molecular map of the rearranged $\mathrm{Y}$ chromosome (+, sequence present; -,sequence absent) 